Revista Iberoamericana, Vol. LXXIX, Núm. 243, Abril-Junio 2013, 329-334

\title{
(DIS)LOCACIONES NARRATIVAS: ARTE Y LITERATURA ACTUAL EN LA REPÚBLICA DOMINICANA Y CUBA
}

\author{
Magdalena LÓPEZ \\ Universidade de Lisboa \\ Arturo Matute Castro \\ Denison University
}

“El lugar no reside en un territorio”, declara Édouard Glissant para demoler cualquier definición del ser enraizado en un absoluto. En un intento por establecer lo que el poeta martiniqueño denomina el "pensamiento archipiélago", presentamos un conjunto de ensayos que sugiere un sistema de relaciones tendiente a movilizar, desestabilizar y, finalmente, dislocar, cualquier pretensión de inmutabilidad discursiva para aprehender producciones literarias y culturales contemporáneas. Dicho conjunto insinúa una urdimbre pocas veces atendida: las de las extensiones, correspondencias y diferencias entre las islas de Cuba y la de la República Dominicana. Raramente se reúnen, en un mismo un mismo volumen, un conjunto de reflexiones críticas sobre la producción cultural de ambas islas. Mientras la primera capitaliza los imaginarios del caribe hispanoamericano, la segunda ha comenzado a suscitar un creciente interés en los estudios académicos. Las circunstancias históricas y políticas de Cuba han conllevado a que a menudo se la compare con Puerto Rico, vista esta última como el otro lado de la moneda por su condición neocolonial. Sin embargo, el estudio de la literatura, la música y el cine de los dos únicos países independientes de las Antillas hispanoamericanas arroja sugestivas construcciones discursivas frente a problemáticas comunes, una de las cuales es, sin duda, la necesidad de reconfigurar las identidades en términos de movilidad ideológica, espacial, racial, sexual y de género en el marco de una región geográfica y cultural cruzada por múltiples desplazamientos.

Dos movimientos concatenados despuntan en el conjunto de ensayos que presentamos en este dossier. Por un lado, el de la necesidad de interpelar los discursos hegemónicos vinculados a la historia dominante (revolucionaria o trujillista) y a los imaginarios que la acompañan; por el otro, el de la revelación de nuevas configuraciones subjetivas que ya no necesariamente dependen de su mera oposición contra aquellos discursos dominantes, sino que, con frecuencia, exhiben cierta originalidad y autonomía constitutiva.

El estudio de una genealogía intelectual, a partir de la figura y obra de Virgilio Piñera, le permite a Rafael Rojas interpelar la canonización del Grupo Orígenes ocurrida a finales de los años ochenta y durante la década de los noventa. A través de la producción 
crítica y creativa relacionada con aquel escritor por parte de autores como Severo Sarduy, César López, Guillermo Cabrera Infante, Víctor Fowler y Antonio José Ponte, asistimos a una perspectiva alternativa que confronta y rebasa el origenismo oficialista esgrimido por Cintio Vitier. Es en la obra de Abilio Estévez, pero sobre todo en la de Antón Arrufat, donde Rojas cifra la continuidad virgiliana de una comunidad letrada tensionada entre la tradición y la heterodoxia. La inscripción de las novelas y ensayos de Arrufat en el escenario literario contemporáneo apuntaría tanto a la identificación con un legado menospreciado durante buena parte de la revolución cubana, como a la legitimación de éste dentro del canon de cara a las jóvenes generaciones.

El ensayo de Damaris Puñales-Alpízar se concentra en evaluar los modos de percibir e intentar representar la realidad cubana en un área tan expuesta a las negociaciones y las imposiciones ideológicas como las coproducciones cinematográficas. Para ello compara tres largometrajes que abarcan los dos periodos en los que a día de hoy se tiende a contextualizar, a partir de la década del sesenta, la literatura y el arte cubanos. Como consecuencia y ejemplo del cine hecho en las primeras décadas revolucionarias se encuentra Soy Cuba (1964); para el caso de la contemporaneidad cubana -léase postrevolucionaria o postsoviética- Puñales-Alpízar aborda las coproducciones Océano (2008) y Lisanka (2009). Su análisis se ejecuta en un doble sentido: hacia el posicionamiento del valor "Cuba" en el ámbito cultural soviético-ruso, y hacia la definición de un metarrelato que entrelaza la historia de ambos países y que resurge como una temática específica en sus literaturas.

Por su parte, Carlos Uxo y Danny Méndez denuncian la persistencia de imaginarios excluyentes tanto en la ciudad letrada dominicana como en la cubana. Con el análisis de dos cuentos de José Alcántara Almánzar, Méndez confirma una normatividad sexual homofóbica. Los personajes travestis son sometidos a la perspectiva homonormativa y dicotómica del autor, conformándolos como subjetividades aberrantes o anormales sin posibilidad de una sexualidad agenciadora. Ceñidos a espacios extremadamente restrictivos; bien intra-textualmente en la ficcionalización de espacios no ordinarios, bien extra-textualmente a través de una crítica literaria sociologizante, los personajes travestis terminan por confirmar, paradójicamente, la dificultad de concebir una alteridad sexual en el imaginario letrado, ya sea el urbano o el nacional en la República Dominicana.

A su vez, Uxo revisa la producción literaria de la generación cubana conocida como la de los novísimos. Ésta ha sido habitualmente destacada por los críticos literarios como una propuesta que rompe con la representación homogénea y triunfalista de la sociedad isleña; se les reconoce a estos autores una denuncia implícita de ciertos desequilibrios sociales, así como una apuesta por un tipo de protagonista con una ética menos maniquea y siempre polémica. Pero contradictoriamente, como demuestra Uxo, la representación del sujeto afrocubano en estas obras distó mucho de romper con estereotipos racistas, lo cual se habría esperado de una literatura caracterizada precisamente por su grado de subversión política. Este ensayo actualiza el análisis de los textos más recientes (sesenta

Revista Iberoamericana, Vol. LXXIX, Núm. 243, Abril-Junio 2013, $329-334$
ISSN 0034-9631 (Impreso) 
y seis novelas en total) de escritores de esta promoción. Plantea la posibilidad de que el surgimiento, aunque mínimo, de ciertos héroes/protagonistas de ascendiente africano ha contribuido a cuestionar abiertamente la situación de alteridad e infrarrepresentación de la población negra al interior de la narrativa cubana.

Fernando Valerio Holguín y Emilio Bejel se ocupan, respectivamente, de develar las dinámicas de legitimización de dos figuras paradigmáticas en ambas islas: Juan Bosch y José Martí. Sin duda alguna, junto con Joaquín Balaguer, Bosch resulta uno de los intelectuales más importantes en la historia intelectual dominicana del siglo xx. A la luz de propuestas teóricas como las de Walter Benjamin sobre la figura del cuentista o la de Raymond Williams sobre la "estructura de pensamiento", el artículo demuestra los vasos comunicantes entre estética y ética, vida y escritura en la figura de Bosch, entendiéndolo como un fenómeno cultural que se posicionó como el sabio y el maestro dentro de un marco ideológico precapitalista.

“José Martí: el ojo del canario. Cine, fotografía y duelo de una mirada” desentraña las recientes articulaciones simbólicas del ícono nacionalista en la película de Fernando Pérez. El autor expone las diversas mediaciones entre el espectador y lo observado para sugerir que, a pesar de la aparente desestabilización que sufre la imagen del héroe, se refuerza su mitificación. El modo en que esto se produce, logrando un fuerte impacto emocional e ideológico, es lo que Bejel explora hasta revelar una reconstrucción retrospectiva y una mirada recíproca que ponen en relación la memoria, la escritura, la fotografía y las secuencias del filme en función de las necesidades políticas del presente.

Los ensayos de Lorna Torrado, Miguel de Mena y Torres-Saillant confirman el dinamismo y las diversas dislocaciones bajo las cuales se fundan las recientes subjetividades caribeñas. Torrado propone una conceptualización del disco El Juidero y los videos que lo acompañan como la reescritura de una historia "otra" dominicana. La música y el baile actuarían como herramientas contradiscursivas que propondrían la experiencia migratoria y la condición trasnacional como ejes de sus discursos de identidad. Recuperando una memoria de la violencia histórica que va desde la trata esclavista trasatlántica, la represión dictatorial y de género, hasta la emigración hacia Puerto Rico y a los Estados Unidos en busca de mejores condiciones de vida, la propuesta de Rita Indiana sugiere una ruptura con la heteronormatividad, el patriarcalismo, el antihaitianismo y los límites geográficos insulares con los que tradicionalmente se ha concebido a la nación dominicana.

Desde otro posicionamiento teórico, Silvio Torres-Saillant pone en duda la teoría de los estudios trasnacionales a la hora de ser aplicada a la literatura caribeña, teniendo en cuenta que esta región, por definición, ha tenido una población en constante flujo migratorio. En su artículo, Torres-Saillant propone un recorrido de lo que denomina una "dispersión segmentada". Con ello se refiere a la experiencia migratoria de la población dominicana a lo largo del tiempo, y a los tipos de discursos y subjetividades generados por esta condición. El autor, además, aporta una reflexión sobre las relaciones

Revista Iberoamericana, Vol. LXXIX, Núm. 243, Abril-Junio 2013, $329-334$
ISSN 2154-4794 (Electrónico) 
de los escritores con la cultura dominante en el lugar de realojamiento cultural y de producción literaria.

La literatura dominicana, enfocada también desde su condición transnacional y diaspórica, centra el ensayo de Miguel D. Mena. Este concibe una extraterritorialidad más allá de su carácter netamente geográfico y fronterizo; igualmente la detecta en la exploración de variedades de la subjetividad, en la contracara o márgenes de narrativas que tradicionalmente privilegiaron, dentro del canon nacional, hablar del espacio público y de asuntos sociales en detrimento de un registro heterogéneo de individualidades. Mena concibe el nuevo ámbito de la literatura quisqueyana como uno cuya nueva soberanía queda circunscrita a los avatares de subjetividades moldeadas por conflictos que atañen a la sociedad moderna, al margen de sus coordenadas espaciales. La obra de autores como Juan Dicent, Rita Indiana Hernández o Rey Andújar funcionaría a la manera de redes abiertas donde significantes narrativos como el pasado histórico y el presente, el aquí y el allá, lo urbano y lo rural quedan subyugados ante el incisivo testimonio de lo privado, tras el impacto de una sociedad degradada.

La emergencia de poéticas, temáticas y preocupaciones autónomas en las literaturas cubana y dominicana es el tópico abordado en las propuestas de Gustavo Pérez Firmat, Rita de Maeseneer y Fernanda Bustamante, Jorge Fornet y Zaida Capote. La reflexión de Pérez Firmat ahonda en la obra poética de dos autores cubanoamericanos o pertenecientes a la llamada “generación 1.5”: Orlando González Esteva y Ricardo Pau-Llosa. Su recorrido hermenéutico se guía por las trazas que una conciencia de exilio deja en la escritura de ambos. Este trabajo, sin embargo, abarca implícitamente un campo reflexivo más amplio, pues valora los vínculos entre el lenguaje elegido para hacer la literatura y el lugar de residencia, o las identificaciones culturales y la apropiación-territorialización-de ciertas realidades de un modo no empírico sino por la vía del conocimiento afectivo y la afinidad estética. Pérez Firmat teoriza la posibilidad de erigir una literatura que, pensando la nación desde su realidad inaprensible y escribiéndola desde un lugar transfronterizo, constituya en sí misma una gnosis que desentrañe y preserve lo que sea que se entienda como un sentimiento (o una performance) de la nacionalidad.

De Maeseneer y Bustamante focalizan su estudio en la materialidad del cuerpo, en las marcas que alteran su integridad, como trasunto metafísico-simbólico de las principales obsesiones de la literatura caribeña en general, y dominicana en particular. Estas autoras analizan el cuerpo como un topos donde la historia deja su marca, sus lesiones hacen de la piel el archivo donde permanece la violencia social que afecta a la región, entendida esta última también en su extensión diaspórica. Ambas autoras acometen obras emblemáticas en tres narradores muy influyentes dentro de la narrativa caribeña de hoy (Rita Indiana Hernández, Rey Emmanuel Andújar y Junot Díaz). Leen en ellas la representación del cuerpo -circunscrito a modalidades específicas de género, raza y clase social- como un microespacio que expone una recepción perturbada, por

Revista Iberoamericana, Vol. LXXIX, Núm. 243, Abril-Junio 2013, $329-334$
ISSN 0034-9631 (Impreso) 
parte del sujeto, de los efectos de políticas neoliberales y de traumas de la historia nacional aún sin solventar.

Como el título del ensayo así lo anuncia, Fornet expone la productividad literaria que se suscitó en Cuba a partir de la década del noventa con la llegada de incertidumbres económicas e ideológicas. A través del análisis de cuatro novelas cubanas producidas en los últimos diez años, asistimos a subjetividades que parecen expresar obsesiones coincidentes. La perspectiva desde el lugar de los perdedores, el tema de la migración y la necesidad de reafirmación de una voz propia son algunas constantes. Pero quizá la problemática más reveladora en los textos de Ena Lucía Portela, Margarita Mateo Palmer, Alberto Guerra y hasta en el de Leonardo Padura sea la de concebir la lectura, la escritura y el mundo de los intelectuales como espacios de doble filo. Metáforas de la imposibilidad, los procesos de lectura y escritura también se ofrecen como una invitación al encuentro de significados ocultos y transgresivos capaces de profundizar en una realidad que ciertamente ha abandonado toda certidumbre.

"Los desafíos de la libertad", de Capote, parte de la evidencia de una situación diferencial dentro de la literatura escrita por mujeres en la Cuba del presente. Esta nueva condición se refleja tanto en un incremento de la presencia editorial como en una exploración inédita de temáticas y técnicas narrativas. El artículo no sólo contrarresta el silencio de la crítica respecto a la exigua presencia de autoras en las antologías sobre la nueva narrativa insular; también le hace justicia al ofrecer un registro de los conflictos y preocupaciones, de las propuestas estéticas que estas obras añaden al corpus literario insular, al cual por mérito propio enriquecen y abigarran. Además de hacer un detallado examen de una categoría específica dentro del panorama narrativo, este trabajo se detiene, entre otros, en textos como los de Ena Lucía Portela, Gleyvis Coro o Aida Bahr por la complejidad que aportan al debate de lo nacional y a cómo se ubica la literatura dentro de este cuestionamiento.

En "Literatura afro-femenina en la República Dominicana” Dawn Duke aborda también problemáticas de género, pero lo hace desde una óptica inusualmente paradójica. La académica explora la complejidad inherente al constructo de la identidad afrofemenina en la literatura dominicana, logrando trascender la denuncia de un discurso hispanista y antihaitiano oficial para demostrar cómo diversas escritoras -entre ellas Sherezada (Chiqui) Vicioso, Yolonka Nacidit-Perdomo y la muy reconocida Aída Cartagena Portalatín-, han conseguido cuestionar este discurso situando lo femenino, pero sobre todo lo negro, en su justo lugar histórico mediante una estrategia discursiva no contracultural de la nación. De este modo la reivindicación del sujeto femenino negro se propone simultáneamente como confrontación y como complemento de la nación en un movimiento ético de inclusión de un componente "racial” negado histórica y socialmente.

Este conjunto de ensayos, sucintamente expuesto, procuró partir del entendido de que cualquier aproximación a las diversas producciones contemporáneas de ambas islas no sólo precisa de la remoción de fronteras normativas, sino que también debe situarse en

\footnotetext{
Revista Iberoamericana, Vol. LXXIX, Núm. 243, Abril-Junio 2013, 329-334 ISSN 0034-9631 (Impreso) ISSN 2154-4794 (Electrónico)
} 
las hendiduras de éstas últimas. De este modo, las desestabiliza en múltiples recorridos que sólo pueden ser evaluados desde la contingencia de un entramado ético ajeno a la noción de territorio. Este dossier, por lo tanto, no resulta concluyente sino más bien sintomático del "lugar” cultural de las últimas décadas en la República Dominicana y Cuba. Al siempre actual y debatible discurso que piensa, construye y ancla una(s) idea(s) de lo caribeño, arrimamos esta antología de saberes que visibiliza una geografía cultural bullente y derramada hacia espacios, lo mismo físicos que especulativos, hasta ahora pendientes de ser explorados.

$\begin{array}{lllll}\text { Revista Iberoamericana, Vol. LXXIX, Núm. 243, Abril-Junio 2013, } & \text { 329-334 } \\ \text { ISSN 0034-9631 (Impreso) }\end{array}$ 